\title{
POLITIKK
}

\section{Xi Jinping og Kinas utenrikspolitiske ambisjoner}

\author{
Jo Inge Bekkevold \\ Institutt for forsvarsstudier (IFS)
}

\begin{abstract}
Sammendrag
Xi Jinping er Kinas mektigste leder siden Deng Xiaoping. Denne artikkelen analyserer i hvilken grad Kinas mer selvhevdende utenriks- og sikkerhetspolitikk de siste årene er drevet frem av Xi, eller om den er et resultat av mer strukturelle endringer i form av at Kinas høye økonomiske vekst over fire tiår har endret den internasjonale maktbalansen i Kinas favør. Teoriretningen nyklassisk realisme - hvor det internasjonale systemet anses som uavhengig variabel, mens trusseloppfatningen til utenrikspolitiske beslutningstakere og statsstruktur er de to viktigste mellomliggende variablene i utformingen av et lands utenrikspolitikk - brukes som analyseverktøy. Artikkelen starter med en gjennomgang av Kina og den internasjonale maktbalansen, etterfulgt av en analyse av Xis ambisjoner og syn på Kinas rolle i internasjonal politikk, og hvorvidt Kinas statsstruktur styrker eller svekker Xis evne til å giennomføre sine utenrikspolitiske ambisjoner. Artikkelen konkluderer med at Xi Jinping kom til makten i Beijing nettopp på et tidspunkt da landets myndigheter og befolkning for alvor begynte å innse hvordan Kinas vekst endret den internasjonale maktbalansen i deres favør. Ved å identifisere at Kina nå går inn i en «ny æra», har Xi løftet seg selv opp som symbol på Kinas inntog som verdens ledende stormakt ved siden av USA. Aktøren Xi har til fulle utnyttet det handlingsrommet strukturendringene ga ham, både nasjonalt og internasjonalt.
\end{abstract}

Nøkkelord: Kina $\cdot$ Xi Jinping $\cdot$ utenrikspolitikk $\cdot$ nyklassisk realisme

\footnotetext{
^Kontaktinformasjon: Jo Inge Bekkevold, e-post: jib@ifs.mil.no

(C)2018 Jo Inge Bekkevold. This is an Open Access article distributed under the terms of the Creative Commons Attribution 4.0 International License (http://creativecommons.org/licenses/by/4.0/), allowing third parties to copy and redistribute the material in any medium or format and to remix, transform, and build upon the material for any purpose, even commercially, provided the original work is properly cited and states its license.

Citation: Fo Inge Bekkevold (2018).Xi finping og Kinas utenrikspolitiske ambisjoner, 76:259-268. http://dx. doi.org/10.23865/ intpol.v76.1353
} 


\section{fo Inge Bekkevold}

Xi Jinping har siden han ble valgt til partileder i 2012 gradvis fremstått som Kinas mektigste leder siden Deng Xiaoping. Etter bare noen få dager som Kinas nye leder holdt Xi en tale i Kinas nasjonalmuseum i Beijing hvor han lanserte "Den kinesiske drøm» som sitt slagord (Xinhua 2013), med lovnader om å levere velferd til landets innbyggere og gjenopprette Kinas posisjon som en stormakt i internasjonal politikk. Kina har de siste årene ført en gradvis mer proaktiv og selvhevdende utenriks- og sikkerhetspolitikk, og jeg skal i denne artikkelen analysere i hvilken grad Kinas mer ambisiøse politikk er drevet frem av Xi Jinping, eller om den er et resultat av at høy økonomisk vekst $\mathrm{i}$ fire tiår har endret den internasjonale maktbalansen $\mathrm{i}$ Kinas favør.

Betydningen av aktør versus struktur i utformingen av utenrikspolitikk er en gammel debatt. I boken «Man, the State and War» fra 1959 identifiserte Kenneth Waltz tre analysenivåer - statsledere, statsstruktur og det internasjonale systemet som alle på sin måte bidrar til å forklare hvorfor stater går til krig. Waltz kalte analysenivåene for 'images' og hevdet at en fullverdig analyse av et lands utenrikspolitikk må ta hensyn til alle tre nivåene: "The vogue of an image varies with time and place, but no single image is ever adequate» (1959: 225). Utover på 1990-tallet bidro flere ledende forskere til utformingen av teorien nyklassisk realisme i studiet av utenrikspolitikk (Christensen 1996, Schweller 1998, Wohlforth 1993, Zakaria 1998). Ifølge Gideon Rose er det internasjonale systemet uavhengig variabel i denne teorien, mens trusseloppfatningen til utenrikspolitiske beslutningstakere og statsstruktur er de to viktigste mellomliggende variablene i utformingen av et lands utenrikspolitikk (1998).

Nyklassisk realisme er et godt egnet verktøy for å studere Xi Jinpings rolle i Kinas mer ambisiøse utenrikspolitikk, og jeg starter derfor artikkelen med en gjennomgang av Kina og den internasjonale maktbalansen, etterfulgt av en analyse av Xis ambisjoner og syn på Kinas rolle i internasjonal politikk. Jeg ser deretter på hvordan Kinas statsstruktur styrker eller svekker Xis evne til å gjennomføre sine utenrikspolitiske ambisjoner, og har valgt å gjøre dette gjennom en kort analyse av følgende åtte faktorer: Xi Jinpings maktposisjon, betydningen av formell versus uformell makt, Xis kontroll med landets utenrikspolitikk, nasjonalisme, evne til å bygge siømakt, Sørkinahavspolitikken, Silkeveiprosjektet (Belt \& Road Initiative - BRI) og internasjonal handel.

\section{Kina og den internasjonale maktbalansen}

Nyklassisk realisme identifiserer maktposisjon i det internasjonale systemet som den viktigste forklaringen på de lange linjer $\mathrm{i}$ et lands utenrikspolitikk (Rose 1998: 150-151) og anerkjenner at stater $i$ et internasjonalt system preget av anarki ikke er fornøyd med sikkerhet, men vil forsøke å kontrollere og påvirke sine omgivelser (Rose 1998: 152), Gilpins observasjon at rike og mektige stater vil sette seg større og mer ambisiøse målsetninger, inkludert sikkerhetspolitiske (1981:22-23, 94-95), er i 
tråd med nyklassisk realisme. Vi bør med andre ord ikke bli overrasket om Kina i takt med sin styrkede posisjon i det internasjonale systemet også får større ambisjoner, og Kinas relative maktposisjon i det internasjonale systemet har endret seg radikalt siden Deng Xiaoping på slutten av 1970-tallet lanserte sin reformpakke.

I 1980 utgjorde Kinas bruttonasjonalprodukt (BNP) mindre enn en tidel av USAs og en femtedel av Japans. Innen Jiang Zemin kom til makten i 1989, hadde Kinas BNP falt ytterligere relativt sett i forhold til USA og Japan, og Kinas forsvarsutgifter utgjorde ved slutten på Den kalde krigen kun tre prosent av USAs. Til tross for imponerende veksttall gjennom hele 1990-tallet var Kina fortsatt kun rangert som verdens sjette største økonomi da Hu Jintao kom til makten i 2002, med et BNP som var så vidt større enn Italias. Men i løpet av det neste tiåret gjorde Kinas vekst store utslag på den internasjonale maktbalansen, slik at Xi Jinping i 2012 tok over som leder av verdens nest største økonomi og nest største forsvarsbudsjett, og siden 2012 har Kinas posisjon styrket seg ytterligere. Mens Kinas BNP i 2012 utgjorde 53 prosent av USAs, vil Kinas BNP ifølge estimater fra Det internasjonale valutafondet (IMF) allerede i 2023 utgiøre hele 88 prosent av USAs (IMF 2018). Mens de samlede forsvarsutgiftene til Japan, Sør-Korea, India og Russland i 2002 var dobbelt så store som Kinas, var Kinas forsvarsutgifter i 2017 betydelig større enn disse landenes samlede forsvarsbudsjetter (SIPRI 2018). Verden har trolig aldri sett en tilsvarende rask endring i den internasjonale maktbalansen i fredstid. Mye tyder på at vi nå står i startgropen på et nytt bipolart internasjonalt system dominert av USA og Kina (Tunsjø 2018).

\section{Xi Jinpings utsyn på verden}

$\mathrm{Xi}$ Jinping tok over et Kina med betydelig større ressurser og en annen internasjonal maktposisjon enn hva hans forgjenger $\mathrm{Hu}$ Jintao hadde til rådighet ti år i forveien, og dette har påvirket Xis utenrikspolitiske ambisjoner og syn på Kinas rolle i internasjonal politikk. På begynnelsen av 1990-tallet la Deng Xiaoping grunnlaget for strategien «hold en lav profil, unngå å ta lederskap» (tao guang yang hui), som ble bærebjelken i Kinas utenrikspolitikk de neste to tiårene (Chen/Wang, 2011). 'Fredfull vekst'politikken lansert på begynnelsen av 2000-tallet var en videreføring av Dengs 'lav profil'-strategi, og da det internasjonalt ble stilt spørsmålstegn ved om 'fredfull' og 'vekst' kunne være to forenlige konsepter, skiftet Kina raskt navn på sin nye politikk til 'fredfull utvikling' (China State Council 2005, Zheng 2005, Glaser \& Medeiros 2007). G-2 konseptet, opprinnelig lagt frem av amerikanske forskere i 2005, fikk mye oppmerksomhet under finanskrisen, da det for første gang ble tydelig at Kina var i ferd med å stå frem som den nye polen i internasjonal politikk ved siden av USA, men kinesisk side avviste dette konseptet. Under finanskrisen oppstod det også en debatt om hvorvidt Beijing Consensus var en bedre vekstmodell enn markedsliberale Washington Consensus, men Beijing avviste bestemt noen ambisjon om å promotere sin modell overfor andre utviklingsland. 
Fordi en endring i den internasjonale maktbalansen er gradvis, og da særlig i fredstid, er det gjerne nødvendig med en utløsende faktor for at beslutningstakere blir oppmerksomme på hvilke muligheter eller begrensninger dette innebærer (Rose 1998, Zakaria 1998, Christensen 1996). For Kina sin del var summen av den globale finanskrisen i 2008-2009, Beijing-OL i 2008, Shanghai EXPO i 2010 og det faktum at Kinas økonomi passerte Japans og ble verdens nest største i 2010, en slik utløsende faktor. Alle disse begivenhetene på rekke og rad i løpet av to år bidro til at lederskapet i Beijing begynte å se på Kinas makt og rolle i internasjonal politikk med nye øyne. Samtidig med at Kina inntok en konstruktiv rolle i G-20 prosessen under finanskrisen, så man konturene av en selvhevdende og mer ambisiøs utenriks- og sikkerhetspolitikk. I 2009 oppførte kinesiske marinefartøy seg uvanlig aggressivt overfor det amerikanske overvåkningsfartøyet USNS Impeccable i Sørkinahavet. I januar 2010, som svar på amerikansk våpensalg til Taiwan, kansellerte Kina høynivåmøter med USA. I juli 2010 protesterte Kina for første gang kraftig mot USAs årlige felles marineøvelse med Sør-Korea i Gulehavet. Samme år fikk man en radikal økning i antallet kinesiske militærfly som utfordret japansk luftterritorium.

Det har blitt diskutert i hvor stor grad disse episodene egentlig innebar en fundamental endring i kinesisk politikk, eller om det hele skyldtes at andre land nå oppfattet Kinas politikk annerledes på grunn av landets nye maktposisjon (Johnston 2013, Yahuda 2013). Det har videre vært debattert om Kinas mer ambisiøse politikk var resultat av en bevisst ny utenrikspolitisk linje fra Kinas ledelse, eller om politikken var resultat av en fragmentering av landets utenrikspolitikk (Gill 2013, Jakobson 2016). Mest trolig var det en kombinasjon av alle disse faktorene: økte ambisjoner, fragmentering og endring $\mathrm{i}$ andre lands syn på Kina. Selv om endringene i Kinas politikk var godt synlige allerede under Hu Jintaos tid, så var Hu fortsatt forsiktig med å ta internasjonalt lederskap. Så sent som i desember 2010 rykket Kinas visestatsminister og øverste utenrikspolitiske talsmann Dai Bingguo ut i kinesiske medier med et forsvar for 'fredfull vekst' politikken (Dai 2010). Det skulle imidlertid snart komme et taktskifte i Beijing.

Med Xi Jinping fikk Kina inn en leder med større bevissthet rundt Kinas nye maktposisjon, og allerede under sitt første besøk til USA som Kinas leder i 2013 foreslo Xi 'a new type of Great Power relations' i forholdet til USA og signaliserte at Kina ønsket å bli behandlet som en stormakt på linje med USA (Zeng \& Breslin, 2016). Da USAs nye president Donald Trump tidlig snakket om proteksjonisme og 'America First', benyttet Xi World Economic Forum i januar 2017 til å hevde at Kina er rede til å ta lederskap og beskytte internasjonal frihandel. Med sitt 'Kina i en ny æra'-konsept, lansert på Partikongressen i Beijing i oktober 2017, ga Xi det offisielle stemplet på en dreining i Kinas storstrategi som har pågått i noen år allerede. I Xi Jinpings æra skal Kina bygge økonomisk makt, myk makt og militær makt, og Kina er ikke lenger bekymret for å ta lederskap eller å være en modell for andre utviklingsland (Bekkevold 2018, Swaine 2018). Det er med andre ord ingen tvil om at Kinas økte makt har ført til økte ambisjoner, og som leder har Xi Jinping vært 
bevisst Kinas nye posisjon og har spilt en sentral rolle i å utforme en ny storstrategi som gjenspeiler Kinas nye maktposisjon i internasjonal politikk.

\section{Kinas statsstruktur og Xis evne til å implementere}

Det er imidlertid ikke nok å sette seg store utenrikspolitiske ambisjoner; som statsleder må man også være i stand til å implementere ambisjonene. I analysen av statsstruktur som mellomliggende variabel er nyklassisk realisme opptatt av å se på lederskapets evne til å mobilisere politisk enighet og oppslutning i opinionen samt å skaffe til veie ressurser til større endringer i utenrikspolitikken (Schweller 2004, Lobell, Ripsman og Taliaferro 2009). Statsstruktur defineres med andre ord bredere enn politisk system og de muligheter og begrensinger som ligger $i$ byråkratiet. I vårt tilfelle kreves det at Xi Jinping evner å sikre oppslutning om sin politikk i partiets ledelse og $\mathrm{i}$ befolkningen, og at han er i stand til å mobilisere tilstrekkelig med ressurser til større prosjekter og politiske tiltak som styrker Kinas maktposisjon.

Xi Jinping ble på den 18. Partikongressen i 2012 tildelt alle de tre sentrale ledervervene i Kina: leder av både Kommunistpartiet og Militærkommisjonen samt statsoverhode i gavn av posisjonen som President. Xi fikk dermed fra starten av et sterkere mandat enn forgjengerne Hu Jintao og Jiang Zemin i sin tid hadde. Fordi $\mathrm{Xi}$ i løpet av kort tid også tok ledelsen over en rekke nyopprettede kommisjoner med ansvar for landets sikkerhetspolitikk, militære og økonomiske reformer, iverksatte den mest omfattende anti-korrupsjonskampanjen i moderne tid og initierte en opprydningsaksion i PLA, ble han allerede i 2014 omtalt som Kinas mektigste leder siden Deng Xiaoping (Economy 2014). Enkelte hevdet endog at Xi er den mektigste lederen i Kina siden Mao Zedong (The Economist 2014). På den 19. Partikongressen høsten 2017 fikk Xi flere av sine støttespillere inn i sentrale posisjoner, og som første leder siden Mao fikk han sitt tankegods - «Xi Jinping's thought on socialism with Chinese characteristics for the new age»- skrevet inn i partiets statutter mens han fortsatt er i posisjon (Fewsmith 2018). Videre fikk Xi på Folkekongressen våren 2018 gjennomslag for å utvide presidentperioden fra to til tre perioder, noe som åpner for at han kan sitte som president frem til 2028 (Miller 2018). Ingen kinesisk leder siden Deng på 1980- og begynnelsen av 90-tallet har hatt en sterkere posisjon enn Xi Jinping nå har til å utmeisle sin politikk. Xi har dessuten en rikere verktøykasse enn Deng hadde tilgjengelig til å implementere sin politikk (Bekkevold 2017). Til tross for at markedet får en gradvis større rolle i økonomien, har den kinesiske staten og landets lederskap fortsatt et så godt grep om Kinas økonomi at de raskere enn de fleste andre land kan mobilisere store ressurser på kort varsel (Bekkevold 2015, 2012).

Xi er imidlertid i motsetning til Deng Xiaoping avhengig av formell makt for å implementere sin politikk. Xi Jinpings far Xi Zhongcun var en av Deng Xiaopings viktigste støttespillere i det kinesiske kommunistpartiet. En slik bakgrunn gir tyngde i kinesisk politikk, men Bo Xilais fall som politiker i $2012 \mathrm{er}$ det fremste eksemplet på at 


\section{fo Inge Bekkevold}

familierøtter lengst inn i kommunistpartiets indre sirkler ikke er noen garanti for suksess. Xi Jinping fremstår som en mer moderne og karismatisk leder enn sin forgjenger $\mathrm{Hu}$ Jintao, og Xis kone er en av Kinas mest berømte sangerinner. Dagens politiske system i Kina begrenser imidlertid betydningen av karisma hos en politisk leder. Xi har en rikere verktøykasse og mer formell makt enn noen annen kinesisk leder i moderne tid, men han har ikke en posisjon i kraft av personlig autoritet slik som Deng Xiaoping fikk utover på 1980- og 90-tallet (Bekkevold 2016, 2015, 2012, Bo 2016).

Xi har også re-sentralisert kontrollen med utenrikspolitikken (Swaine 2018). I de siste årene av $\mathrm{Hu}$ Jintaos lederskap så man en fragmentering av utenrikspolitikken, i den forstand at flere departementer, provinser og ikke minst PLA iverksatte tiltak med negative konsekvenser for Kinas relasjoner til naboland og USA uten å koordinere med landets øverste lederskap i Beijing (Jakobson 2016). Selv om Xi har tatt et tydeligere grep om utenrikspolitikken enn sine forgjengere og dreid politikken $i$ en mer ambisiøs retning, er det ikke nødvendigvis et stort brudd med utenrikspolitikken til hans forgjengere. Xi har for eksempel beholdt Wang Huning (nå medlem av Politbyrået) som en sentral rådgiver på internasjonale spørsmål, til tross for at Wang først gjorde karriere under Jiang Zemin og Hu Jintao.

Kinas kommunistparti har i flere tiår bevisst bygd opp et nasjonalistisk narrativ for å styrke partiets legitimitet i befolkningen, og en viktig del av dette narrativet er Vestens ydmykelse av Kina på 1800-tallet og USAs/Vestens fortsatt pågående forsøk på å forhindre Kinas fremvekst som stormakt (Fewsmith 2016). Med slagordet «Den kinesiske drøm» spilte Xi Jinping fra dag én på disse nasjonalistiske strengene for å sikre oppslutning om stormaktambisjonene og en mer selvhevdende utenrikspolitikk. I lanseringen av sitt slagord hentet Xi blant annet inspirasjon fra en bok med samme tittel, forfattet i 2010 av Liu Mingfu, oberst i Folkets frigjøringshær (PLA), som argumenterte for betydningen av Kina som sterk militærmakt i en post-amerikansk æra (Liu 2010). På grunn av sin sterke maktbase vil Xi i stor grad kunne kontrollere og styre disse strømningene i befolkningen, men det er en risiko for at en fremtidig svakere leder vil gi etter for folkets krav om en tøffere utenrikspolitikk, ikke minst i Kinas Japan-politikk (Reilly 2017).

Kinas forsøk på å bygge sjømakt er spydspissen i landets stormaktambisjon og den største utfordringen for USAs strategiske tilstedeværelse i regionen. Grunnpilarene i Kinas sjømaktstrategi ble lagt lenge før Xi kom til makten (Erickson 2016). Allerede tidlig på 2000-tallet begynte kinesiske myndigheter å bygge et narrativ om behovet for sjømakt, hvor Kinas tidligere ydmykelser ble koblet til fraværet av en sterk marine, og at sjømakt derfor er nødvendig hvis Kina skal ha ambisjon om igjen å bli en stormakt (Ross 2009, Tobin 2018). Kinas første hangarskip Liaoning ble sjøsatt et par måneder før Xi ble valgt til partileder i 2012. Xi Jinping har imidlertid omfavnet Kinas sjømaktstrategi med full styrke og gjort den til en essensiell del av sin politikk.

Sørkinahavet har blitt symbolet på Kinas mer selvhevdende utenriks- og sikkerhetspolitikk. I likhet med sjømaktambisjonene var Beijings Sørkinahavspolitikk i 
stor grad på plass før Xi kom til makten, men også på dette politikkområdet har Xi likevel satt sine tydelige spor. Fra og med tidlig 2014 har Kina bygget ut kunstige rev flere steder i Sørkinahavet og har nå begynt å utplassere våpensystemer på enkelte av disse revene. Gjennom sitt lederskap av "Central Maritime Rights Protection Leading Small Group» fra og med 2012 har Xi vært sentral i beslutningen og implementeringen av denne politikken (You 2017, Glaser 2015).

Mens Xi Jinping må dele 'æren' for Kinas sjømaktstrategi og Sørkinahavspolitikk med sine forgjengere, er Silkeveiprosjektet (BRI) Xis eget prosjekt. Xi lanserte BRI i 2013, den gang kjent som "One Belt, One Road» (OBOR), bestående av både en maritim og en landbasert del. Selv om kinesiske myndigheter fastholder at dette først og fremst er økonomisk politikk med formål å styrke det økonomiske samarbeidet $\mathrm{i}$ hele Eurasia, så er omfanget av prosjektet så stort at det har geopolitiske konsekvenser (Bekkevold \& Engh 2017). Både de økonomiske midlene kinesiske myndigheter har stilt til rådighet til implementeringen av BRI og de ressursene Kinas utenrikstjeneste bruker på initiativet, samt hvordan BRI nå er integrert i nesten ethvert politiske tiltak iverksatt i Kina, viser med all tydelighet at Xi evner å mobilisere store ressurser for å iverksette sine ambisjoner.

Xi er tilsynelatende ikke redd for å gå inn i en omfattende handelskrig med USA. Mens Kina under $\mathrm{Hu}$ Jintao og Jiang Zemin gjentatte ganger justerte sin handelsog valutapolitikk i møte med amerikansk kritikk, har Xi valgt å svare på Donald Trumps omfattende restriksjoner på import fra Kina med samme mynt rettet mot amerikansk eksport til Kina. Hvorvidt Xis taktikk er resultat av hans personlighet og lederstil eller av Kinas nye økonomiske muskler, er imidlertid usikkert. Det er

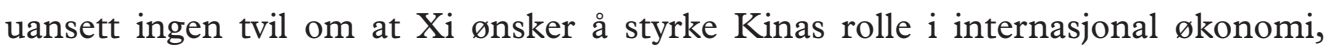
og der Trump for eksempel trekker USA ut av den regionale handelsavtalen med land i Øst-Asia (Trans-Pacific Partnership), benytter Xi anledningen til å sette fart på Kinas egen frihandelsavtale i regionen - Regional Comprehensive Economic Partnership (RCEP).

\section{Konklusjon}

Xi Jinping kom til makten i Beijing på et tidspunkt da landets myndigheter og befolkning for alvor begynte å innse hvordan Kinas vekst endret den internasjonale maktbalansen i deres favør. Xi kom med andre ord i stor grad til dekket bord som følge av endringer i den internasjonale strukturen, men han så umiddelbart hvordan denne situasjonen kunne utnyttes både til sin egen og landets fordel. Ved å identifisere at Kina nå går inn i en "ny æra", har Xi løftet seg selv opp som symbol på Kinas inntog som verdens ledende stormakt ved siden av USA. Xi har styrket sin maktposisjon, han har resentralisert kontrollen med landets utenrikspolitikk, og han spiller bevisst på nasjonalistiske strenger som støtter oppunder hans stormaktambisjoner for Kina. Kinas ambisjoner som sjømakt ble utformet lenge før Xi kom til makten, men han har videreført og styrket denne politikken, og han 


\section{fo Inge Bekkevold}

har gjort det samme med hensyn til Sørkinahavet. Xi har i tillegg lansert sin egen storslåtte strategi for Kina i Silkeveiprosjektet. Aktøren Xi har til fulle utnyttet det handlingsrommet strukturendringene ga ham, både nasjonalt og internasjonalt. Min gjennomgang av Xi Jinpings rolle i utformingen av Kinas utenrikspolitikk har dessuten vist at det er nødvendig å ta hensyn til alle de tre analysenivåene identifisert av Waltz: lederskap, statsstruktur og det internasjonale systemet. Det gjenstår å se hvorvidt Xis stormaktambisjoner for Kina er bærekraftige eller ikke, og om de vil utløse sterke motreaksjoner i regionen og i USA, men det er en annen debatt.

\section{Om forfatteren}

Jo Inge Bekkevold er seniorrådgiver ved Institutt for forsvarsstudier. Bekkevold har forfattet og redigert flere bøker om Kina og internasjonal politikk. Han er tidligere diplomat i den norske utenrikstjenesten.

\section{Litteratur}

Bekkevold, Jo Inge (2018) "China's Grand Strategy in a New Era», IAPS Dialogue, Institute of Asia and Pacific Studies, University of Nottingham, January. Tilgjengelig på https://iapsdialogue.org/2018/02/12/chinasgrand-strategy-in-a-new-era. Lesedato 30.05.2018.

Bekkevold, Jo Inge (2016) «Xi vs Deng: Stronger China, Harder Choices», China Policy Institute: Analysis, University of Nottingham, 03.11.2016. Tilgjengelig på https://cpianalysis.org/2016/11/03/xi-vs-dengstronger-china-harder-choices/. Lesedato 30.05.2018.

Bekkevold, Jo Inge (2012) «Stat, marked og Kinas nye lederskap» i Jo Inge Bekkevold \& Henning Kristoffersen, (red.) Kinas økonomi. Oslo: Gyldendal Akademisk (243-266).

Bekkevold, Jo Inge \& Sunniva Engh (2017) «Silk Road Diplomacy: China’s Strategic Interests in South Asia» i Sten Rynning (red.) South Asia and the Great Powers: International Relations and Regional Security. London: I.B. Tauris.

Bekkevold, Jo Inge \& Stig Stenslie (2015) «Xi Jinpings makt og avmakt: Styringsutfordringer i implementeringen av Kinas nye økonomiske modell», Internasjonal politikk, 73 (2): 183-208.

Bo Zhiyue (2016) "China's Fifth-Generation Leaders: Characteristics of the New Elite and Pathways to Leadership» i Robert S. Ross \& Jo Inge Bekkevold (red.) China in the Era of Xi finping: Domestic and Foreign Policy Challenges. Georgetown: University Press.

Chen Dingding \& Wang Jianwei (2011) «Lying Low No More? China's New Thinking on the Tao Guang Yang Hui Strategy", China: an international journal, 9 (4): 196-216.

China State Council (2005) China's Peaceful Development Road. Beijing: State Council Information Office. Tilgjengelig på http://www.china.org.cn/english/2005/Dec/152669.htm. Lesedato 31.05.2018.

Christensen, Thomas J. (1996) Useful Adversaries: Grand Strategy, Domestic Mobilization, and Sino-American Conflict, 1947-1958. Princeton: Princeton University Press.

Dai Bingguo (2010) "Adhere to the Path of Peaceful Development», Xinhua 06.12.2010.Tilgjengelig på https:// china.usc.edu/dai-bingguo-“adhere-path-peaceful-development”-dec-6-2010. Lesedato 04.06.2018.

Economy, Elisabeth C. (2014) «China's Imperial President. Xi Jinping Tightens His Grip», Foreign Affairs, 93 (6): 80-91.

Erickson, Andrew S. (2016) «China’s Naval Modernization, Strategies, and Capabilities» i Jo Inge Bekkevold \& Geoffrey Till (red.) International Order at Sea. How it is challenged. How it is maintained. London: Palgrave Macmillan.

Fewsmith, Joseph (2018) "The $19^{\text {th }}$ Party Congress Ringing in Xi Jinping's New Age», China Leadership Monitor, 2018 (55). Tilgjengelig på https:/www.hoover.org/sites/default/files/research/docs/clm55-jf-final.pdf

Fewsmith, Joseph (2016) "The Challenges of Stability and Legitimacy» i Robert S. Ross \& Jo Inge Bekkevold (red.) China in the Era of Xi Finping: Domestic and Foreign Policy Challenges. Georgetown: University Press $(92-114)$. 


\section{Xi finping og Kinas utenrikspolitiske ambisjoner}

Gill, Bates (2013) «From peaceful rise to assertiveness? Explaining changes in China's foreign and security policy under Hu Jintao". Artikkel presentert ved SIPRI-konferansen The Hu Jintao Decade in China's Foreign and Security Policy (2002-2012): Assessments and Implications. Stockholm: Stockholm International Peace Research Institute.

Gilpin, Robert (1981) War E Change in World Politics. Cambridge: Cambridge University Press.

Glaser, Bonnie S. (2015) «China's Maritime Rights Protection Leading Small Group - Shrouded in Secrecy." Asia Maritime Transparency Initiative 11.11.2015. Tilgjengelig på https://amti.csis.org/chinasmaritime-rights-protection-leading-small-group-shrouded-in-secrecy/. Lesedato 05.06.2018.

Glaser, Bonnie S. \& Evan S. Medeiros (2007) «The Changing Ecology of Foreign Policy-Making in China:The Ascension and Demise of the Theory of "Peaceful Rise"", The China Quarterly, 190: 291-310.

IMF (2018) World Economic Outlook, April 2018. Tilgjengelig på http:/www.imf.org/external/pubs/ft/weo/2018/ 01/weodata/index.aspx. Lesedato 06.06.2018.

Jakobson, Linda (2016) "Domestic Actors and the Fragmentation of China's Foreign Policy» i Robert S. Ross \& Jo Inge Bekkevold (red.) China in the Era of Xi finping: Domestic and Foreign Policy Challenges. Georgetown: University Press.

Johnston, A. I. (2013) "How new and assertive is China's new assertiveness?», International Security, 37 (4): $7-48$.

Liu Mingfu (2010) Zhongguo Meng: hou Meiguo shidai de daguo siwei zhanlue dingwei (The China Dream: The great power thinking and strategic positioning of China in the post-American era), Zhongguo youyi chuban gongsi (China Friendship Publishing House).

Lobell, Steven E., Norrin M. Ripsman \& Jeffrey W. Taliaferro (2009) Neoclassical Realism, the State and Foreign Policy. Cambridge: Cambridge University Press.

Miller, Alice (2018) "Only Socialism Can Save China: Only Xi Jinping Can Save Socialism», 2018 (56). Tilgjengelig på https://www.hoover.org/sites/default/files/research/docs/clm56am.pdf.

Reilly, James (2017) «Popular Nationalism and Economic Interests in China's Japan Policy» i Robert S. Ross \& Øystein Tunsjø (red.) Strategic Adjustment and the Rise of China: Power and Politics in East Asia. Ithaca: Cornell University Press.

Rose, Gideon (1998) «Neoclassical Realism and Theories of Foreign Policy», World Politics, 51 (1): 144-72.

Ross, Robert S. (2009) «China's Naval Nationalism: Sources, Prospects, and the U.S. Response», International Security, 34 (2): 46-81.

Schweller, Randall L. (2004) «Unanswered Threats: A Neoclassical Realist Theory of Underbalancing», International Security, 29 (2): 159-201.

Schweller, Randall L. (1998) Deadly Imbalance: Tripolarity and Hitler's Strategy of World Conquest. New York: Columbia University Press.

SIPRI (2018) Military expendicture database. Tilgjengelig på https:/www.sipri.org/sites/default/files/1_ Data $\% 20$ for $\% 20$ all $\% 20$ countries $\% 20$ from $\% 201988 \%$ E2\%80\%932017\%20in $\% 20$ constant $\% 20$ \%282016\%29\%20USD.pdf. Lesedato 28.05.2018.

Swaine, Michael D. (2018) "Chinese Views of Foreign Policy in the 19th Party Congress", China Leadership Monitor, 2018 (55). Tilgjengelig på https://www.hoover.org/sites/default/files/research/docs/clm55-msfinal.pdf.

The Economist (2014) «The rise and rise of Xi Jinping» 20.09.2014. Tilgjengelig på http://www.economist. $\mathrm{com} /$ news/leaders/21618780-most-powerful-and-popular-leader-china-has-had-decades-must-use-theseassets-wisely-xi\#. Lesedato 15.10.2014.

Tobin, Liza (2018) «Beijing's Strategy to Build China into a Maritime Great Power», Naval War College Review, 71 (2): $17-48$.

Tunsjø, Øystein (2018) The Return of Bipolarity in World Politics. China, the United States, and Geostructural Realism. N.Y.: Columbia University Press.

Waltz, Kenneth N. (1959) Man, the State andWar: a theoretical analysis. Columbia University Press: New York. Waltz (1979) Theory of international politics. Illinois: Waveland Press.

Wohlforth, William Curti (1993) The Elusive Balance: Power and Perceptions during the Cold War. Ithaca, N.Y.: Cornell University Press.

Xinhua (2013) "President Vows to Bring Benefits to People in Realizing “Chinese Dream"» 17.03.2013. Tilgjengelig på http://news.xinhuanet.com/english/china/2013-03/17/c_132240052.htm. Lesedato 03.01. 2014.

Yahuda, Michael (2013) "China's new assertiveness in the South China Sea", fournal of Contemporary China, 22 (81): 446-59. 


\section{fo Inge Bekkevold}

You Ji (2017) «Xi Jinping and PLA Centrality in Beijing's South China Sea Dispute Management», China: An International fournal, 15 (2): 1-21.

Zakaria, Fareed (1998) From Wealth to Power:The Unusual Origins of America's World Role. Princeton: Princeton University Press.

Zeng Jinghan \& Shaun Breslin (2016) «China's 'new type of Great Power relations': a G2 with Chinese characteristics?», International Affairs, 92 (4): 773-794.

Zheng Bijian (2005) China's Peaceful Rise. Washington D.C.: Brookings Institution Press. 